\title{
Electrocatalytic sulfite biosensor with human sulfite oxidase co-immobilized with cytochrome c in a polyelectrolyte-containing multilayer
}

\author{
Roberto Spricigo • Roman Dronov $\cdot$ Fred Lisdat • \\ Silke Leimkühler • Frieder W. Scheller • \\ Ulla Wollenberger
}

Received: 1 July 2008 /Revised: 19 September 2008 / Accepted: 23 September 2008 / Published online: 21 October 2008

(C) Springer-Verlag 2008

\begin{abstract}
An efficient electrocatalytic biosensor for sulfite detection was developed by co-immobilizing sulfite oxidase and cytochrome $\mathrm{c}$ with polyaniline sulfonic acid in a layerby-layer assembly. QCM, UV-Vis spectroscopy and cyclic voltammetry revealed increasing loading of electrochemically active protein with the formation of multilayers. The sensor operates reagentless at low working potential. A catalytic oxidation current was detected in the presence of sulfite at the modified gold electrode, polarized at $+0.1 \mathrm{~V}$ (vs. $\mathrm{Ag} / \mathrm{AgCl} 1 \mathrm{M} \mathrm{KCl}$ ). The stability of the biosensor performance was characterized and optimized. A 17-bilayer electrode has a linear range between 1 and $60 \mu \mathrm{M}$ sulfite with a sensitivity of $2.19 \mathrm{~mA} \mathrm{M}{ }^{-1}$ sulfite and a response time of $2 \mathrm{~min}$. The electrode retained a stable response for 3 days with a serial reproducibility of $3.8 \%$ and lost $20 \%$ of sensitivity after 5 days of operation. It is possible to store the sensor in a dry state for more than 2 months. The multilayer electrode was used for determination of sulfite in unspiked and spiked samples of red and white wine. The recovery and the specificity of the signals were evaluated for each sample.
\end{abstract}

R. Spricigo · R. Dronov · S. Leimkühler · F. W. Scheller •

U. Wollenberger $(\bowtie)$

Institute of Biochemistry and Biology, University of Potsdam,

Karl-Liebknecht Strasse 24-25,

14476 Golm, Germany

e-mail: uwollen@rz.uni-potsdam.de

R. Spricigo

Max-Planck-Institute of Colloids and Interfaces,

Am Mühlenberg 1,

14476 Golm, Germany

F. Lisdat

Biosystems Technology, Wildau University of Applied Sciences, 15745 Wildau, Germany
Keywords Bioelectrocatalysis $\cdot$ Sulfite $\cdot$ Sulfite oxidase $\cdot$ Cytochrome c $\cdot$ Multilayer

\section{Introduction}

Sulfite is used as an additive in food and beverages to prevent oxidation and bacterial growth, and to control enzymatic reactions during production and storage $[1,2]$. Sulfite has been the subject of legislation as a food additive since the discovery that it causes asthmatic attacks and allergic reactions to hypersensitive people [3, 4]. In the USA and EU a label is required for a food or beverage containing more than $10 \mathrm{mg} \mathrm{kg}^{-1}$ or $10 \mathrm{mg} \mathrm{L}^{-1}$ sulfite $[5,6]$. Several approaches have been proposed for the determination of sulfite, such as titration [7], high-performance liquid chromatography [1, 8, 9], flow injection analysis [10], and spectrophotometric and electrochemical methods [11-16]. One example is the Monier-Williams method, based on acid-base titration, which has been recommended by the Association of Official Analytical Chemists (AOAC) [7]. However, this method is labour-intensive, time consuming and lacks precision. Methods using ion exchange chromatography or direct amperometric detection cause a rather quick fouling of the electrode, which is a serious drawback of direct oxidation. It is therefore of considerable interest to develop an enzyme biosensor for the detection of sulfite since this would allow fast, selective and accurate determination of sulfite without the need for significant sample preparation, or fouling of the electrode.

Sulfite oxidase (SO) is a complex metalloprotein containing the molybdenum cofactor (Moco) and a cytochrome $b_{5}$-type heme, and both cofactors are located in two different domains of the protein which are connected by a 
flexible loop region. SO catalyses the oxidation of sulfite to sulfate, the terminal reaction in the catabolism of the sulfur-containing amino acids cysteine and methionine in mammals. The enzyme is located in the intermembrane space of mitochondria, and the equivalents derived from sulfite oxidation are passed on to cytochrome c (cyt c) via the heme iron of cytochrome $b_{5}$ [17-19] according to Eq. (1):

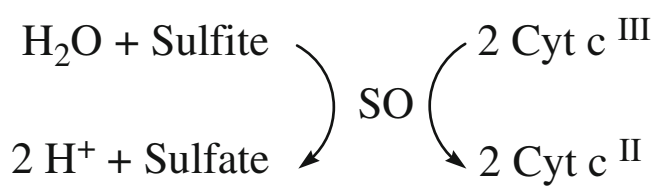

The enzyme is also active with artificial redox mediators such as ferricyanide and tetrathiafulvalene/tetracyanoquinodimethane (TTF/TCNQ) [20]. It has been shown for bovine hepatic SO that oxygen can also serve as an electron acceptor to form hydrogen peroxide [21]. Amperometric sulfite biosensors monitoring the formation of hydrogen peroxide by SO have been developed recently $[11,22]$. However, due to the high working potential of these biosensors, compounds in the analysed samples might be directly oxidized which then generates unspecific signals.

A biosensor involving direct electron transfer (ET) communication between the enzyme and the electrode is expected to be more specific. Previously, direct oxidation of the heme domain of chicken SO was obtained at gold electrodes modified with self-assembled monolayers (SAMs) of synthetic, terminally functionalized alkanethiols
[23]. This approach allowed the detection of $10-100 \mu \mathrm{M}$ sulfite. Another approach to obtain selectivity for sulfite was to decrease the working potential of the sulfite biosensor using cyt $\mathrm{c}$ as mediator between $\mathrm{SO}$ and the electrode [12]. However, since only a limiting amount of protein was in contact with the electrode, the sensitivity of this electrode was low.

Recently, more complex protein architectures were described in which SO and cyt $\mathrm{c}$ were immobilized directly by protein-protein interaction [24] and by the help of the anionic polyelectrolyte PASA [25]. As illustrated in Scheme 1 in the latter approach multilayers of SO (green) and cyt $\mathrm{c}$ (red) are assembled on a monolayer of cyt $\mathrm{c}$ on gold and PASA (blue) was used as an electrostatic glue. A monolayer of cyt $\mathrm{c}$ is obtained by electrostatic adsorption on a self-assembled mercaptoundecanoic acid layer (hatching) on the gold electrodes (yellow) [26]. The overall charge of the alkanethiol layer is negative; cyt $\mathrm{c}$ is a basic protein and can therefore interact with negatively charged surfaces. Noncovalently bound cyt $\mathrm{c}$ retains mobility and thus provides a good communication not only with the electrode but also with the proteins of the surrounding [27]. SO was co-immobilized together with cyt $\mathrm{c}$ by the layer-bylayer technique using a PASA interlayer. PASA has not just a structural function: surface-enhanced resonance Raman analysis of PASA-cyt c multilayers demonstrate that electron exchange between cyt $\mathrm{c}$ and the polyelectrolyte is possible [28]. The multilayer electrode generates a catalytic current upon addition of sulfite as a result of series of intramolecular, intermolecular and interfacial ET steps. Sulfite is oxidized to sulfate at the Moco domain of SO. The electrons are then delivered to the heme $b_{5}$ domain of
Scheme 1 Schematic of the expected multilayer structure of SO and cyt c, adsorbed layerby-layer onto a chemically modified gold surface together with a negatively charged polyelectrolyte (PASA, blue). SO (green) oxidizes sulfite to sulfate and transfers electrons via heme $b_{5}$ to cyt c (red) and hence to the gold electrode (yellow) via cyt c-cyt c interaction

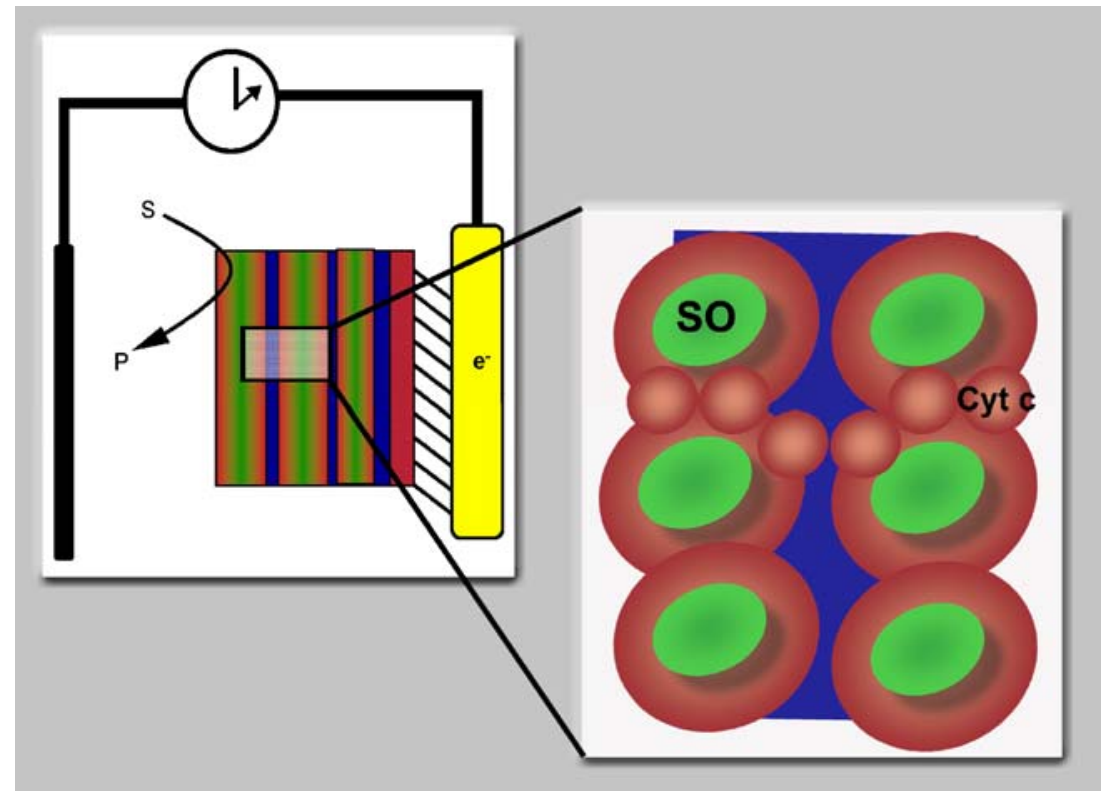


$\mathrm{SO}$ and then transferred to the closest molecule of cyt $\mathrm{c}$ (red balls), which transfers electrons further to the electrode via other cyt c molecules while reoxidizing itself. As the last step, the promoter (hatching)-modified gold electrode allows fast electron transfer with cyt $\mathrm{c}$.

The total amount of SO immobilized increased with the number of assembled layers. The increase in protein loading on the sensor surface and the low working potential provided a significant improvement of sensitivity and selectivity of the biosensor.

Here, we describe the characterization, optimization and application of a sulfite biosensor based on the electrocatalytic capability of SO/cyt c PASA layer-by-layer architecture.

\section{Materials and methods}

\section{Materials}

Horse heart cytochrome c (cyt c), catalase (CAT, E.C. 1.11.1.6, $\left.1,990 \mathrm{U} \mathrm{mg}^{-1}\right)$ and sodium molybdate were purchased from Sigma (Steinheim, Germany). 11-Mercapto-1-undecanoic acid (MUA), 11-mercapto-1-undecanol (MU), polyallylamine hydrochloride (PAA) and sulfonated polyaniline (PASA) were purchased from Aldrich (Taufkirchen, Germany). Potassium dihydrogen phosphate, dipotassium hydrogen phosphate, disodium sulphite, trishydroxymethyl aminomethane, sodium chloride, sodium phosphate and potassium chloride were purchased from Merck (Darmstadt, Germany). Ampicillin sodium salt and imidazole were purchased from Roth (Karlsruhe, Germany). Isopropyl $\beta$-D-1-thiogalactopyranoside (IPTG) was from Duchefa Biochemie (Haarlem, Netherlands) and Ni-NTA resin was from Qiagen (Hilden, Germany). Other reagents were of analytical reagent grade and used as received. All solutions were prepared with $18 \mathrm{M} \Omega$ Millipore water (Eschborn, Germany).

\section{Buffers}

Potassium phosphate buffer was prepared from dipotassium phosphate and potassium diphosphate, with the $\mathrm{pH}$ adjusted with potassium hydroxide or phosphoric acid. Buffer 1, $0.5 \mathrm{mM}$ potassium phosphate buffer, $\mathrm{pH} 5$, was used for the preparation of the PASA solution. Buffer 2, $0.5 \mathrm{mM}$ potassium phosphate buffer, $\mathrm{pH} 7$, was used for the preparation of the cyt c-SO, PAA and washing solution. Buffer 3, $5 \mathrm{mM}$ potassium phosphate buffer, $\mathrm{pH} 7$, was used for the preparation of the cyt $\mathrm{c}$ monolayer. Buffer 4, $5 \mathrm{mM}$ Tris buffer, $2 \mathrm{mM} \mathrm{KCl}, \mathrm{pH} \mathrm{8.5,} \mathrm{was} \mathrm{used} \mathrm{for} \mathrm{the} \mathrm{recording} \mathrm{of} \mathrm{the}$ voltammograms of the multilayer electrodes. Buffer 5 , comprising $50 \mathrm{mM}$ sodium phosphate buffer, $300 \mathrm{mM} \mathrm{NaCl}$, $\mathrm{pH} \mathrm{8}$, was used for SO purification.
Sulfite oxidase expression and purification

His-tagged human SO was purified after expression in E. coli TP1000 cells containing plasmid pTG718 as described previously [29]. For protein expression a preculture of the cell strain containing the expression plasmid was grown aerobically at $37{ }^{\circ} \mathrm{C}$ overnight in Luria-Bertani medium (LB) supplemented with $150 \mu \mathrm{g} \mathrm{ml}^{-1}$ ampicillin. This culture was diluted 1:50 with LB supplemented with ampicillin, $1 \mathrm{mM} \mathrm{Na}_{2} \mathrm{MoO}_{4}$ and $20 \mu \mathrm{M}$ IPTG and grown aerobically at $30{ }^{\circ} \mathrm{C}$ for $24 \mathrm{~h}$. Cells were harvested by centrifugation at $8,000 \mathrm{rpm}$ for $5 \mathrm{~min}$. The cell pellet was resuspended in buffer 5 , and lysed by several passages through a French pressure cell (SLM). After centrifugation at 13,200 rpm for $30 \mathrm{~min}$, the supernatant was added to $1.5 \mathrm{ml} \mathrm{Ni}$-NTA resin per litre of cell growth. The slurry was poured into a column and the soluble fraction of the extract was allowed to flow through the resin. The column was washed with 10 volumes of buffer 5 containing $10 \mathrm{mM}$ imidazole followed by a wash with the same volume of buffer 5 containing $20 \mathrm{mM}$ imidazole. The His $_{6}$-tagged protein was eluted with buffer 5 containing $250 \mathrm{mM}$ imidazole. Finally the buffer of the protein was changed to $1 \mathrm{mM}$ potassium phosphate buffer, $\mathrm{pH} 7$, by two series of dialysis and concentrated to $850 \mu \mathrm{M}$.

\section{Sulfite oxidase assay}

The concentration of SO was quantified with a UV spectrophotometer (Shimadzu, UV-2401PC) by using the molar extinction coefficient of $113,000 \mathrm{~cm}^{-1} \mathrm{M}^{-1}$ at $413 \mathrm{~nm}$ [30]. The activity of $\mathrm{SO}$ was assayed by monitoring the reduction of cytochrome $\mathrm{c}$ at $550 \mathrm{~nm}$ in the presence of sodium sulfite [30].

\section{Electrochemical measurements}

All the electrochemical measurements were performed in 1-ml batch cells using $\mathrm{Ag} / \mathrm{AgCl} / 1 \mathrm{M} \mathrm{KCl}$ reference (Biometra, Germany) and homemade counter electrodes constructed from 0.5-mm Pt wire (Goodfellow, Bad Nauheim, Germany). The working electrodes were modified gold wires (diameter $0.5 \mathrm{~mm}$ ) from Goodfellow (Bad Nauheim, Germany). Cyclic voltammetric and amperometric experiments were performed with the $\mathrm{CH}$ instrument Model 750A (Austin, USA).

Cyt c monolayer electrode preparation

Gold wire electrodes (diameter $0.5 \mathrm{~mm}$ ) were cleaned by boiling in $2 \mathrm{M} \mathrm{KOH}$ and successive incubations overnight in concentrated $\mathrm{H}_{2} \mathrm{SO}_{4}$ and 10 min in concentrated $\mathrm{HNO}_{3}$ according to the method of Katz et al. [31]; the electrodes were carefully rinsed with Millipore water after each step. The cleaned electrodes were incubated in a mixture of $5 \mathrm{mM}$ MUA/5 mM MU (1:3, v/v) for $48 \mathrm{~h}$. After rinsing 
with water, the MU/MUA-modified electrodes were incubated in $600 \mu \mathrm{l}$ of $20 \mu \mathrm{M}$ cyt c in buffer 3 overnight to allow cyt $\mathrm{c}$ adsorption and were finally rinsed carefully with water and buffer 3 .

\section{Multilayer electrode preparation}

Freshly prepared cyt c monolayer electrodes were successively incubated in PASA solution $\left(0.2 \mathrm{mg} \mathrm{ml}^{-1}\right.$ in buffer 1) and cyt c/SO solution (respectively 20 and $1 \mu \mathrm{M}$ in buffer 2) for $10 \mathrm{~min}$ each, with three washing steps in buffer 2 in between [25]. In the same way the additional PASA and PAA $\left(0.2 \mathrm{mg} \mathrm{ml}^{-1}\right.$ in buffer 2) protective layers were adsorbed. For stabilisation the multilayer electrodes were treated in buffer 1 for $30 \mathrm{~min}$ at $40{ }^{\circ} \mathrm{C}$ [32].

\section{Multilayer preparation for UV-Vis spectroscopy}

Cyt $\mathrm{c}$ was adsorbed onto the walls of polystyrene cuvettes (Roth, Germany) by overnight incubation in $30 \mu \mathrm{M}$ cyt $\mathrm{c}$ in buffer 3. The following assembly of PASA and SO/cyt c was similar to that used in the electrode preparation, i.e. the modified cuvettes were filled successively with PASA solution $\left(0.2 \mathrm{mg} \mathrm{ml}^{-1}\right.$ in buffer 1$)$ and cyt c/SO solution (20 $\mu \mathrm{M}$ cyt $\mathrm{c}$ and $1 \mu \mathrm{M}$ SO in buffer 2) for $10 \mathrm{~min}$ each with three washing steps in between. Spectra were recorded using a Shimadzu UV-2401PC spectrophotometer.

\section{Sulfite determination}

Sulfite was measured amperometrically by applying a constant potential of $+100 \mathrm{mV}$ and constantly stirring the solution. The background current was allowed to settle to a baseline and a series of 5- to $30-\mu 1$ aliquots of a $1 \mathrm{mM}$ sulfite stock solution were added to $1 \mathrm{ml}$ of buffer 4 . The enzyme reaction was monitored via the oxidation of the cyt $\mathrm{c}$ until steady state values were reached. Real sample analysis was performed using red and white wine from local stores before and after spiking with a known concentration of sulfite. The unspiked and spiked samples were analysed after a 200 - to 1,000-fold dilution with buffer 4 .

For detection of interferences the wine samples were initially diluted ten times in buffer 4 and incubated with $10 \mu \mathrm{M}$ SO $(0.5 \mathrm{kU})$ and $50 \mu \mathrm{M}$ CAT $(25 \mathrm{kU})$ overnight at $4{ }^{\circ} \mathrm{C}$ in sealed vials. A sample without SO was used as positive control. The interferences were detected by using the multilayer electrode and compared with the positive control.

\section{Electrode storage}

Freshly prepared multilayer electrodes were stored in buffer 2 or in a dry state at $4{ }^{\circ} \mathrm{C}$. The dry state was achieved by simply storing the electrodes without buffer at $4{ }^{\circ} \mathrm{C}$.

\section{Results and discussion}

\section{Biosensor assembly}

$\mathrm{SO}$ and cyt c were co-assembled in multilayers by alternate adsorption of PASA, and the multilayer assembly was analysed by using QCM, UV-Vis spectroscopy and cyclic voltammetry. The change of resonance frequency shows a mass increase after each protein adsorbtion cycle (Fig. 1a). In parallel, the amount of electroactive cyt $\mathrm{c}$ showed a linear increase with an increasing number of proteinpolyelectrolyte bilayers, as reflected in the cyclic voltammograms (Fig. 1b). From the peak area the quantity of electrochemically active cyt $\mathrm{c}$ per single layer was estimated

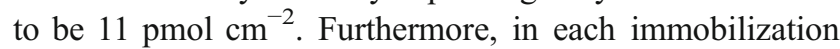
cycle about $0.14 \mathrm{pmol} \mathrm{cm}^{-2}$ active SO was deposited [25]. Spectroscopic data further showed that all immobilized cyt $\mathrm{c}$ molecules contributed to the electrochemical signal (Fig. 1c). Here, an increase of the absorbance at $409 \mathrm{~nm}$ is observed with increasing numbers of PASA-cyt $\mathrm{c} / \mathrm{SO}$ layers deposited on the cuvette. However, the UV-vis spectra do not allow one to distinguish the band contribution of the two heme proteins, since SO and cyt $\mathrm{c}$ absorb light around $410 \mathrm{~nm}$. Nevertheless, clear proof of the activity of $\mathrm{SO}$ was obtained by addition of sulfite which caused the shift of this band and the increase of the absorbance at $550 \mathrm{~nm}$, both well-known symptoms of cyt c reduction (data not shown).

The optimum $\mathrm{pHs}$ to achieve high protein loading and catalytic activity were 5.0 and 7.0 for the PASA and cyt c/SO solutions, respectively. The amount of protein and the ratio of SO/cyt c used for immobilization were also previously optimized. Highest signals were obtained with $1 \mu \mathrm{M} \mathrm{SO}$ and $20 \mu \mathrm{M}$ cyt $\mathrm{c}$ when the ionic strength of buffer was kept low $(0.5 \mathrm{mM})$ to increase the electrostatic interaction [25].

Using this strategy a large quantity of enzyme (SO) and mediator (cyt c) were co-immobilized while maintaining their catalytic and electrochemical activity. As shown in Scheme 1, the SO molecules immobilized in the outer layers are suggested to be in contact with the electrode via the cyt $\mathrm{c}$ network, and the adsorbed proteins thus maintain a certain mobility which allows intermolecular protein interactions. The flexibility has been investigated previously using an approach where SO in solution was able to communicate with a monolayer of cyt $\mathrm{c}$ adsorbed on the gold surface (data not shown). The thickness of a cyt c$\mathrm{SO} /$ cyt c double layer without PASA was calculated by using atomic force microscopy (AFM) to be approximately $10 \mathrm{~nm}$ [24]. Moreover an exhaustive AFM study 
Fig. 1 Increase in protein mass by increasing the number of deposition cycles. a QCM: frequency shift for five successive deposition rounds of $\mathrm{SO} /$ cyt $\mathrm{c}$ and PASA on a monolayer of cyt c-modified gold chip. b CVs of multilayer electrodes at $0.1 \mathrm{~V} \mathrm{~s}^{-1}$ for an increasing number of $\mathrm{SO} /$ cyt $\mathrm{c}$ and PASA bilayers: $4(A), 8(B)$ and $12(C)$. c Spectra showing the rise of the Sorret band at $409 \mathrm{~nm}$ for $6(A)$ and $12(B)$ bilayers on a polystyrene cuvette surface
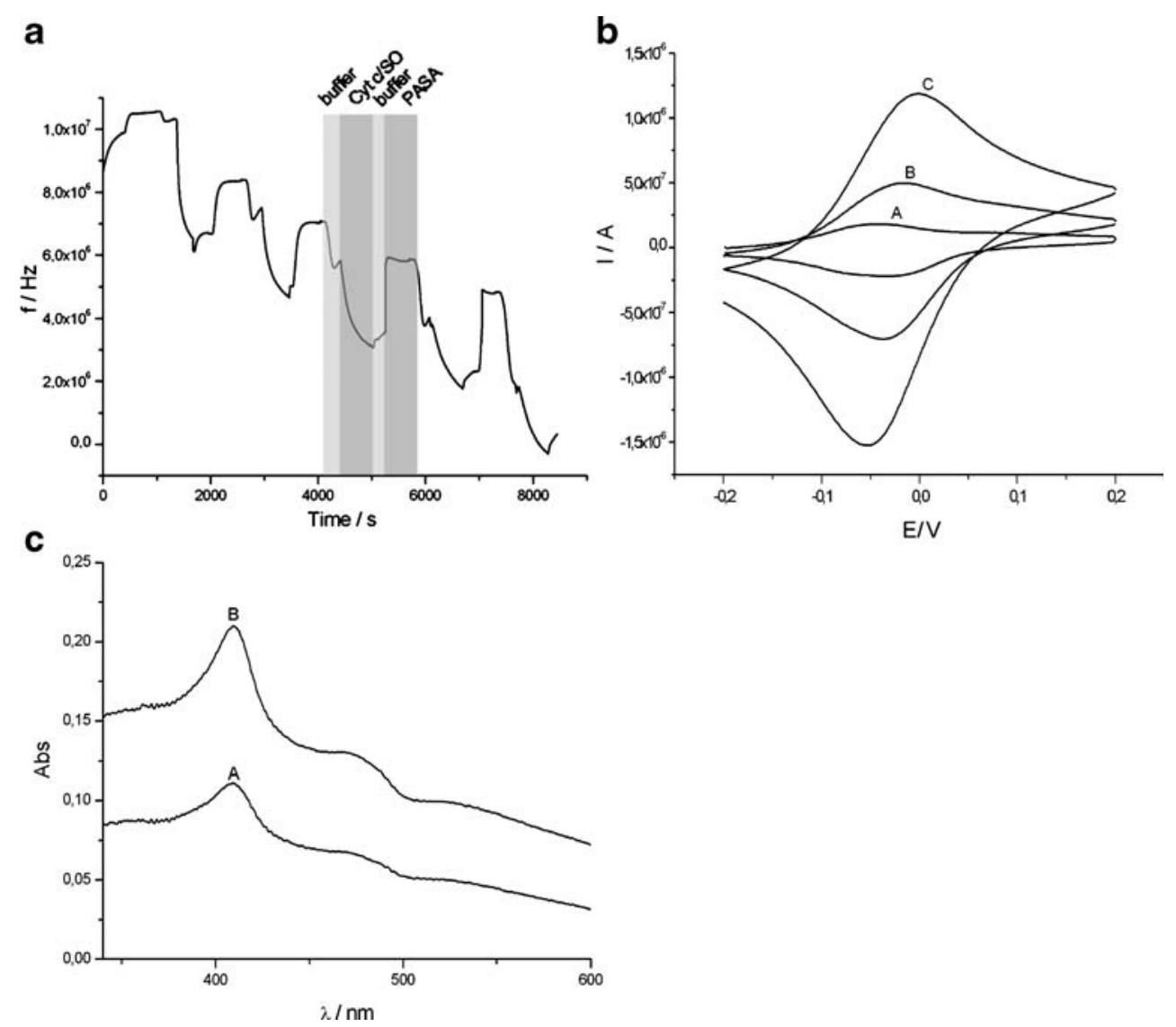

on cyt c/PASA multilayers showed that the intermediate layers are formed as distinguishable units rather than as a mixed layer. The terminating layers of PASA or cyt c determine the surface potential independent of the number of preceding layers, thus producing similar charge and adhesive properties [33].

The addition of sulfite resulted in a rapid increase of oxidation current at a constant potential of $+0.1 \mathrm{~V}$ under hydrodynamic conditions. A stationary value is generally reached within $90 \mathrm{~s}$. With six-layer electrodes the sensitivity was determined to be $1.2 \mathrm{~mA} \mathrm{M}^{-1}$ (Fig. 2).

Additional SO-cyt $\mathrm{c}$ layers resulted in a further increase of the electrocatalytically active protein and a higher sensitivity with a detection limit of sulfite of $1 \mu \mathrm{M}$. The increase of sensitivity of the sensor by increasing the number enzyme layers suggested that the system is still kinetically controlled up to 17 enzyme layers.

The activation energy $\left(E_{\mathrm{a}}\right)$ of the SO reaction was calculated by varying the reaction temperature and applying the Arrhenius equation [34]:

$k=A \exp \left(-E_{\mathrm{a}} / R T\right)$

where $k$ is the reaction rate constant, $A$ the frequency factor, $R$ the universal gas constant, $F$ the Faraday constant and $T$ the temperature. The reaction rate of $\mathrm{SO}$ and cyt $\mathrm{c}$ in solution was determined at different temperatures (278-
$303 \mathrm{~K}$ ) using a spectrophotometer. For determination of $E_{\mathrm{a}}$ of the multilayer the same was done electrochemically in a thermostated cell. The rate $k$ at different temperatures was calculated by using the Nicholson-Shain method [35]. The ratio between catalytic $\left(I_{\text {cat }}\right)$ and uncatalysed $\left(I_{0}\right)$ currents is

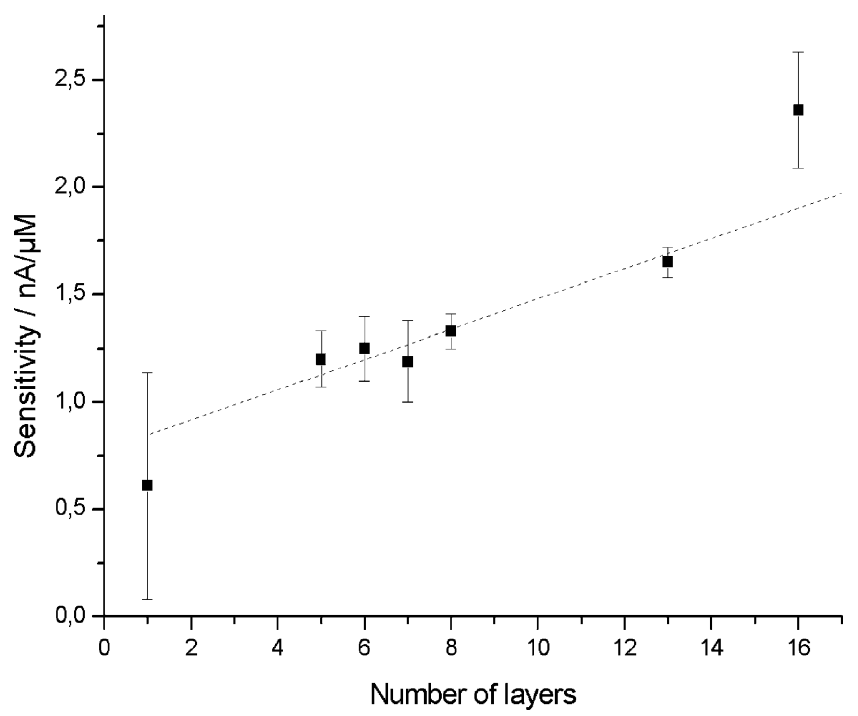

Fig. 2 Dependence of the sensitivity for sulfite on the number of $\mathrm{SO} /$ cyt $\mathrm{c}$ and PASA bilayers (Au/MU, MUA cyt c/(cyt c, SO/PASA) $)$. Amperometric measurements using different sulfite concentrations $(20-30 \mu \mathrm{M})$ in stirred buffer 4 at $+0.1 \mathrm{~V}$ 
proportional to the square root of $k$. In Eq. (2) $n$ is the number of electrons exchanged and $\nu$ the scan rate.

$\left(I_{\text {cat }} / I_{0}\right)^{2}=\lambda=k(R T / n F) / v$

The calculated activation energy of the multilayer electrode system $\left(72.4 \mathrm{~kJ} \mathrm{~mol}^{-1}\right)$ is twice that calculated in solution $\left(44.1 \mathrm{~kJ} \mathrm{~mol}^{-1}\right)$. The obtained values were unexpected since a diffusion limitation, which affects the multilayer structure, would result in a lower activation energy as has been reported for other immobilized enzymes [36]. Thus temperature-driven rearrangements of the multilayer structure may be the cause of these results.

The principle of the biosensor combines sulfite-dependent reduction of $\mathrm{SO}$ and reoxidation by the co-assembled cyt $\mathrm{c}$, which itself is oxidized on the gold electrode by direct electron transfer. The latter reaction was thoroughly investigated and proceeds at considerably lower working potential with only minor effects from other oxidants as compared with $\mathrm{H}_{2} \mathrm{O}_{2}$ detection. The best results, evaluated after the addition of $2 \mathrm{mM}$ sulfite, were obtained with a potential of $+0.1 \mathrm{~V}$ and (vs. $\mathrm{Ag} / \mathrm{AgCl} / 1 \mathrm{M} \mathrm{KCl}$ ), which is a rather small value compared with the potential required for the detection of hydrogen peroxide $(+0.6 \mathrm{~V})$ for the oxygen-dependent reaction of SO [15] and to $+0.3 \mathrm{~V}$ used for a less sensitive cyt c-mediated electrode [12].

The catalytic current at $+0.1 \mathrm{~V}$ depends linearly on the sulfite concentration in the range between 1 and $60 \mu \mathrm{M}(r=$ 0.98) (Fig. 3). Saturation is reached at $200 \mu \mathrm{M}$ sulfite (Fig. 3, inset). An apparent $K_{\mathrm{m}}$ value of $77 \mu \mathrm{M}$ was determined from the concentration dependence. Reduced acces-

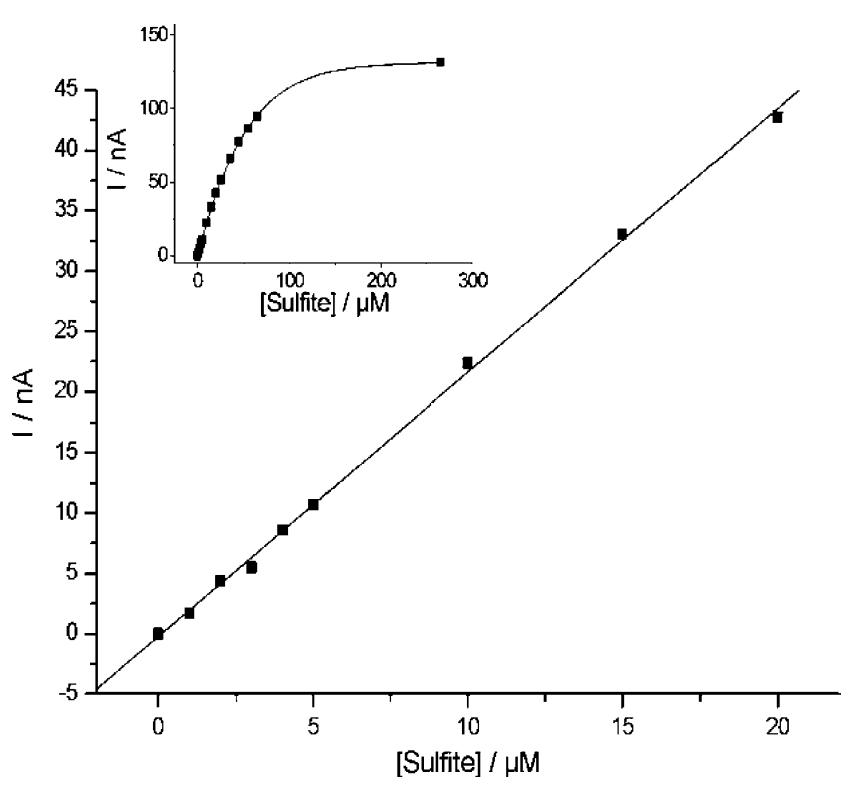

Fig. 3 Dependence of the catalytic current on sulfite concentration for a 17-bilayer multilayer electrode, polarized at $+0.1 \mathrm{~V}$ (linear regression, $r=0.99$ ). Inset shows the whole concentration range investigated sibility and the interaction with PASA might explain the higher $K_{\mathrm{m}}$ value compared with that determined spectroscopically in homogeneous solutions $(1 \mu \mathrm{M}$; data not shown).

\section{Sensor stability}

The response of the sensor was studied over a 5-day period by daily measurements and after storage in buffer at $4{ }^{\circ} \mathrm{C}$. As shown in Fig. 4, 50\% of the sensitivity was retained after 1 week. The observed decrease likely results from the loss of material from the surface. In addition, it was determined that the amount of electrochemically active cyt $\mathrm{c}$ was also reduced, thus a limited leakage is expected to improve the stability of the sensor. To improve the sensor, it was covered with additional polyelectrolyte layers as described before for a single protein multilayer electrode [32]. After the attachment of several cyt $\mathrm{c} / \mathrm{SO}$ layers together with PASA, two additional covering layers of PASA were adsorbed with one layer of polyallyl amine hydrochloride (PAA). This additional barrier improved the stability of the sensor (Fig. 4b). Further stabilisation was obtained after applying a heat treatment step to reorganize and condense the assembled structure. This treatment results in a closer contact of protein and polyelectrolyte as was shown previously for the cyt cPASA multilayers [28]. The electrode showed a stable catalytic response toward sulfite for more than 3 days with $20 \%$ loss of sensitivity after 5 days (Fig. 4 c).

In addition, we analysed the effect of the heat treatment on response time and reproducibility. The additional layers increased the response time for $1 \mathrm{mM}$ sulfite to about $2 \mathrm{~min}$ showing that the charged cover introduced a diffusion restriction into the layer assembly (data not shown).

Another advantage of the supplemental structure is the improved precision of the sulfite sensor response after several series of measurements. Repetitive measurements of sulfite were compared for untreated and stabilized electrodes. The best result was obtained using the additional surface coverage combined with a short heat treatment. The generated catalytic current was within 3.8\% error for eight repetitive measurements with no decrease in signal. The RSD was larger than 5\%. Similar results were obtained for three different electrode preparations.

Furthermore, the long-term stability of the sensor assembly with additional covering layers and after heat treatment was studied during wet and dry storage. Before measurement, the sensors were incubated in buffer for $1 \mathrm{~h}$. In the dry state the multilayer electrode was stable for more than 10 weeks, whereas loss of sensitivity was observed when the sensor was stored in buffer solution (wet) (Fig. 5). The oxidative current generated by each electrode was compared and normalized with the value obtained directly after the multilayer preparation. It is expected that the 
Fig. 4 a Stability of the catalytic current of a multilayer electrode without (squares) and b with additional covering of differently charged polyelectrolyte double layers (circles) and $\mathbf{c}$ with additional covering plus heat treatment (triangles). Error bars result from three measurements. Results based on amperometric detection of $1 \mathrm{mM}$ sulfite in buffer 4 . Between the measurements the multilayer electrodes were stored in buffer 2 at $4{ }^{\circ} \mathrm{C}$

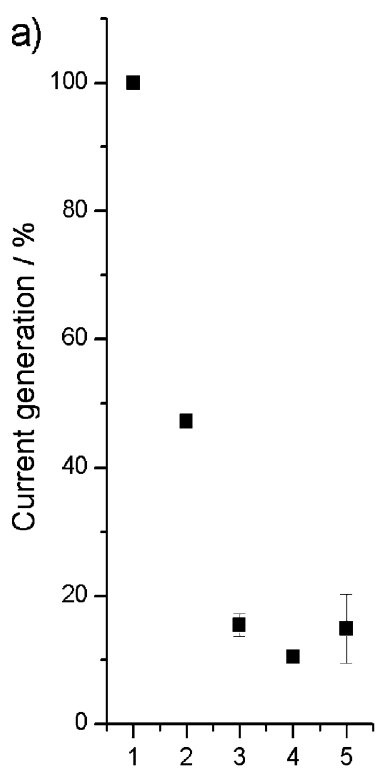

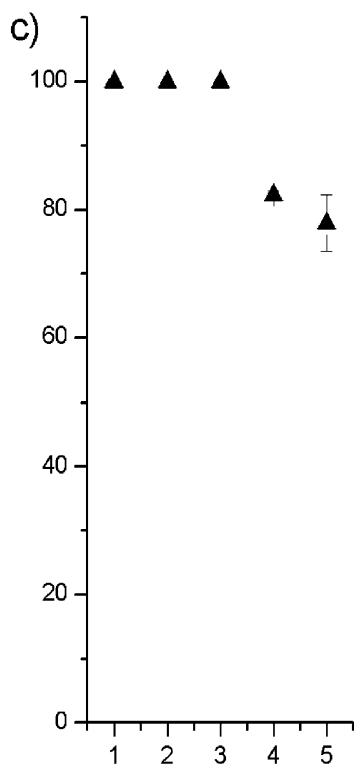

elimination of the buffer resulted in a tighter interaction between the different components. Furthermore, long-term incubation (storage in buffer solution) might also lead to loss of protein from the surface. As became clear from the experiments, the working stability is not very high due to the loss of material from the assembly and not because of the progressive inactivation of the proteins. Stabilisation could therefore be achieved by additional covering layers. On the other hand, the developed structure possesses high storage stability. After 10 weeks of dry storage the electrocatalytic assembly was still working.

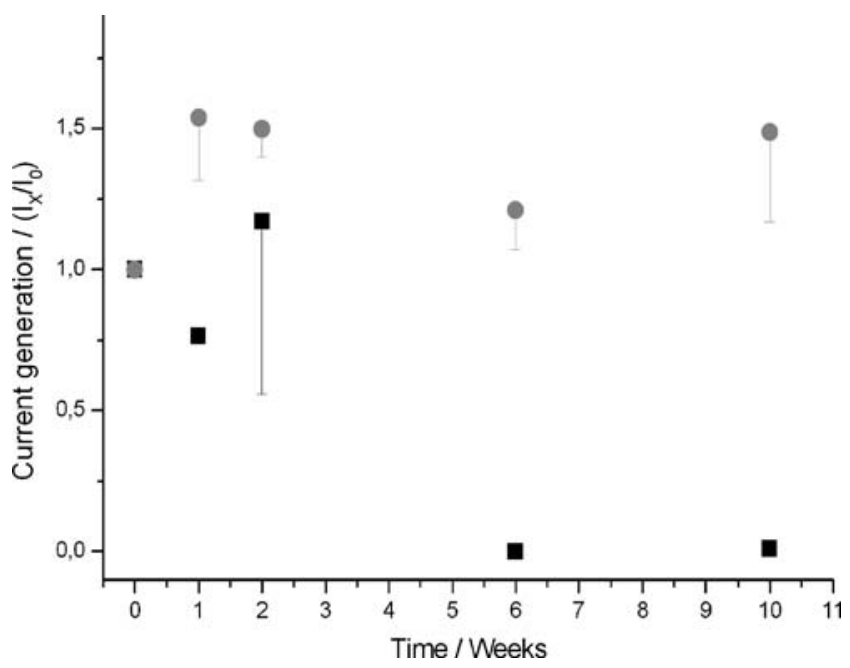

Fig. 5 Catalytic amperometric response for $20 \mu \mathrm{M}$ sulfite of an eightbilayer electrode stored in buffer (squares) and in the dry state (circles) at $4{ }^{\circ} \mathrm{C}$. The dry electrodes were preincubated for $1 \mathrm{~h}$ in buffer before measurement. Error bars from measurement of three different electrodes
Application to real sample analysis

The electrocatalytic biosensor was tested by monitoring white and red wine samples obtained from local stores. Diluted samples and mixtures with the addition of known concentrations of sulfite were analysed. Furthermore, unspecific signals were determined after elimination of sulfite from the sample. To convert all sulfite present in the sample to sulfate, a diluted sample was incubated with $\mathrm{SO}$ and CAT. SO was shown to oxidize sulfite by using molecular oxygen as an electron acceptor [16] by producing hydrogen peroxide. The addition of CAT will rapidly convert the hydrogen peroxide into water and oxygen.

Table 1 Determination of sulfite in white and red wines

\begin{tabular}{llll}
\hline Wine & $\begin{array}{l}\text { Recovery } \\
(\%)\end{array}$ & $\begin{array}{l}\text { Unspecific } \\
\text { signal }(\%)\end{array}$ & $\begin{array}{l}\text { Calculated concentration } \\
(\mathrm{mM} ; \mathrm{ppm})\end{array}$ \\
\hline White 1 R1 & $98 \pm 2$ & 0 & $6.73 \pm 0.35 ; 538 \pm 28$ \\
White 2 R2 & $97 \pm 6$ & 0 & $7.71 \pm 0.48 ; 617 \pm 38$ \\
White 3 R3 & $99 \pm 4$ & 0 & $3.69 \pm 0.49 ; 295 \pm 39$ \\
White 4 R4 & $99 \pm 14$ & 0 & $4.25 \pm 0.30 ; 340 \pm 24$ \\
White 5 R5 & $101 \pm 2$ & 0 & $3.68 \pm 0.64 ; 294 \pm 51$ \\
Red 1 R6 & $86 \pm 3$ & 8 & $2.51 \pm 0.28 ; 201 \pm 22$ \\
Red 2 R7 & $48 \pm 9$ & 33 & $3.36 \pm 0.59 ; 269 \pm 47$ \\
Red 3 R8 & $69 \pm 1$ & 0 & $7.20 \pm 0.60 ; 576 \pm 48$ \\
Red 4 R9 & $102 \pm 9$ & 0 & $3.70 \pm 1.49 ; 296 \pm 119$ \\
Red 5 R10 & $99 \pm 16$ & 30 & $4.42 \pm 0.94 ; 354 \pm 75$ \\
\hline
\end{tabular}

Calculation of the concentration after correction for unspecific signal estimated from the residual signal after SO and CAT incubation and recovery of sulfite in spiked samples. Standard deviation from triplicate measurements 
As shown in Table 1, no unspecific signal was obtained in white wine samples. A small oxidative signal was detected after this treatment with only some red wine samples. Red wine is known to have a high level of polyphenolic antioxidants, which might cause interfering signals (Table 1) $[37,38]$. Thus at the present state of development the sensor is only applicable for determination of sulfite in white wine.

Overall, the high unspecific signals associated with common SO-based sulfite biosensors using the detection of hydrogen peroxide [21] or reduced mediators $[13,20]$ were drastically reduced with the developed multilayer electrode owing to the lower electrode potential by which large oxidation currents in the presence of various antioxidative substances in white wine and also several red wine samples are avoided.

Table 1 shows the results obtained for white and red wines, the recovery and the unspecific signal. The calculated sulfite concentrations are close to or slightly higher than the upper limit set by the European authority [6]. The recovery is nearly $100 \%$ for most wine samples with exceptions for three red wine samples. The assay buffer $\mathrm{pH}$ (8.5) was optimized with respect to the catalytic response [25].

\section{Conclusions}

We have described the development and application of an electrocatalytic multilayer biosensor composed of SO, cyt c and PASA. The biosensor sensitivity increased with the number of layers applied and is dependent on the quantities of SO and cyt c. Moreover, the stability and precision were improved by two different strategies, polyelectrolyte coverage and thermal treatment. The storage stability was enhanced by drying the multilayer self-assembly. This new device was applied to the analysis of real wine samples.

This nanostructured system is very efficient since the reaction within this functional protein assembly and the direct electrochemical cyt $\mathrm{c}$ reoxidation at the modified gold electrode both proceeded very fast. The approach offers flexibility in tuning the sensitivity and the lower detection limit. Thus, samples can be largely diluted, thereby decreasing the risk of interferences and side reactions.

The electrocatalytic biosensor was applicable for sulfite determination in different white wine samples, since these samples did not contain significant amounts of substances interfering with the redox protein and the electrode functioned at the low operating potential. However, some red wines caused an unspecific response. Further improvement is expected when additional enzyme coverings are used to enzymatically eliminate the interferences [39].

Acknowledgements This work was supported by the Cluster of Excellence "Unifying Concepts in Catalysis" program coordinated by the Technische Universitaet Berlin and funded by the Deutsche
Forschungsgemeinschaft and by the Marie Curie program "Early Stage Research Training on Biomimetic Systems" MEST-CT-2004504465 , which are gratefully acknowledged. We thank also K.V. Rajagopalan for the plasmid of SO.

\section{References}

1. Pizzoferrato L, di Lullo G, Quattrucci E (1998) Food Chem 63:275-279

2. Fazio T, Warner CR (1990) Food Addit Contam 7:433-454

3. Vally H, Carr A, El-Saleh J, Thompson P (1999) J Allergy Clin Immunol 103:41-46

4. Vally H, Thompson PJ (2001) Thorax 56:763-769

5. Food labelling: declaration of sulphiting agents (1986) Federal Register 25012-25020

6. EC (2004) Commission Regulation No 1991/2004

7. AOAC (1995) In: Cunnif P (ed) AOAC Official Method 962.16, 16th edn, vol II

8. McFeeters RF, Barish AO (2003) J Agric Food Chem 51:15131517

9. Wei F, Chen MS, Yu L, Chang L, Li DM (1999) Se Pu 17:583-585

10. Thanh NTK, Decnop-Weever LG, Kok WT (1994) Fresenius J Anal Chem 349:469-472

11. Dinckaya E, Sezgintürk MK, Akyimaz E, Ertas FN (2007) Food Chem 101:1540-1544

12. Abass AK, Hart JP, Cowell D (2000) Sensors Actuators B 62: $148-153$

13. Situmorang MDBH, Justin Gooding J, Barnett D (1999) Analyst 124:1775-1779

14. Yilmaz UT, Somer G (2007) Anal Chim Acta 603:30-35

15. Zhao M, Hibbert DB, Gooding JJ (2006) Anal Chim Acta 556:195-200

16. Smith VJ (1987) Anal Chem 59:2256-2259

17. Johnson JL, Hainline BE, Rajagopalan KV (1980) J Biol Chem 255:1783-1786

18. Cohen HJ, Fridovich I (1971) J Biol Chem 246:359-366

19. Howell LG, Fridovich I (1968) J Biol Chem 243:5941-5947

20. Groom CA, Luong JHT, Masson C (1993) J Biotech 27:117-127

21. Sasaki S, Arikawa Y, Shimomura M, Ikebukuro K, Karube I (1997) Anal Commun 34:299-301

22. Svobodova L, Snejdarkova M, Hianik T (2002) Anal Bioanal Chem 373:735-741

23. Ferapontova EE, Ruzgas T, Gorton L (2003) Anal Chem $75: 4841-4850$

24. Dronov R, Kurth DG, Möhwald H, Spricigo R, Leimkühler S, Wollenberger U, Rajagopalan KV, Scheller FW, Lisdat F (2008) J Am Chem Soc 130:1122-1123

25. Spricigo R, Dronov R, Rajagopalan KV, Lisdat F, Leimkühler S, Scheller FW, Wollenberger U (2008) Soft Matter 4:972-978

26. Collinson M, Bowden EF, Tarlov MJ (1992) Langmuir 8:12471250

27. Jin W, Wollenberger U, Kärgel E, Schunck WH, Scheller FW (1997) J Electroanal Chem 433:135-139

28. Grochol J, Dronov R, Lisdat F, Hildebrandt P, Murgida DH (2007) Langmuir 23:11289-11294

29. Temple CA, Graf TN, Rajagopalan KV (2000) Arch Biochem Biophys 383:281-287

30. Rajagopalan KV (1980) In: Coughlan MP (ed) Molybdenum and molybdenum-containing enzymes. Pergamon, Oxford, pp 241-272

31. Katz E, Schlereth DD, Schmidt HL (1994) J Electroanal Chem 367:59-70

32. Beissenhirtz MK, Scheller FW, Lisdat F (2004) Anal Chem $76: 4665-4671$ 
33. Dronov R, Kurth DG, Möhwald H, Scheller FW, Friedmann J, Pum D, Sleytr UB, Lisdat F (2008) Langmuir 24:87798784

34. McNaught AD, Wilkinson A (eds) (1997) IUPAC compendium of chemical terminology, 2nd edn. Blackwell Scientific, Oxford

35. Nicholson RS, Shain I (1965) Anal Chem 37:178-190
36. Carr PR, Bowers LD (1980) Immobilized enzymes in analytical and clinical chemistry. Wiley, New York

37. Corder R, Mullen W, Khan NQ, Marks SC, Wood EG, Carrier MJ, Crozier A (2006) Nature 444:566

38. Giovannini C, Filesi C, D'Archivio M, Scazzocchio B, Santangelo C, Masella R (2006) Ann Ist Super Sanita 42:336-347

39. Wang J, Naser N, Wollenberger U (1993) Anal Chim Acta 281:19-24 